6. Vozniuk, S.T.,Moshinsky, V.S.andother (2017). Peatland resource of the NorthWestern region of Ukraine. NUVGP, Rivne.91 P.

7. Malanchuk, Z.R., Gavrish, V.S., Strikha, V.A., Kirichik, I. M. (2013). Technologies of open pit mining. NUVGP, Rivne. P. 255-277.

8. Inshekov, E. M., Chernyushok, L. M.(2012). Peat as an alternative source for thermal energy, on the example of the paper industry. Kyiv: Sustainable energy development. Technical University of Ukraine "Kyiv Polytechnic Institute named after Igor Sikorsky". P. 240-246. Retrieved from http://en.iee.kpi.ua/files/2012/240-246.pdf

9. Curly, V. P. (2003). Phytomelioration: textbook. Lviv: Svit. 540P.

10. Gray M. Peat resources of Ukraine: current state, prospect of use. Economic and social geography. Scientific Notes № 1. pp. 88-85, (2012).

https://doi.org/10.31713/m1005

\title{
MONITORING OF THE BENCHES AND SIDES STABILITY OF THE QUARRIES
}

Nizametdinov F.K.

Karaganda Technical University, Professor, Doctor of Technical Sciences, Professor, Department of Mine Surveying and Geodesy, Kazakhstan

Ozhigin S.G.

Karaganda Technical University, Professor, Doctor of Technical Sciences, Vice-rector on scientific work, Kazakhstan

Nizametdinov N.F.

Karaganda Technical University, Ph.D., Candidate of Technical Sciences, Senior Lecturer, Department of Mine Surveying and

Geodesy, Kazakhstan

\section{Oralbay A.O.}

Karaganda Technical University, Doctoral student, Department of Development of mineral deposits, Kazakhstan

Abstract. The increase in the volume of opencast mining is facing the main problem of ensuring the stability of the open pit slopes on the planned contour. To achieve this goal, required reliable geomechanical support of the parameters of the slopes of quarry benches and sides, then placing them on the planned contour using special technological schemes of the slopes and constant instrumental monitoring of their condition in an automated mode. The main emphasis in the work has been given to the method of instrumental monitoring of the quarry's arrays state using modern instruments with the analysis of their measurement's accuracy. The approved instrumental methods of monitoring at the open-pit mines of Kazakhstan are presented. 


\section{Introduction}

Forecasting and ensuring the stability of the slopes of quarry benches and sides is one of the most important tasks in open pit mining. When taking into account the factors affecting the stability of open pit slopes, it is necessary to know: the type of deformations, the activity of the destruction process, the frequency of disturbance, the parameters of landslide or collapse, the nature of the slope destruction, the characteristics and conditions of rocks bedding, the duration of the development of deformations, the nature and configuration of the sliding surface. Information of this kind of breaches is impossible to obtain without systematic instrumental surveying monitoring, which serve as the most reliable basis for predicting the state of stability of quarry slopes [1-5].

The main requirements for the production of surveying monitoring of the condition of slopes in open pits are set out in the methodological guidelines [6,7]: systematic visual inspection of the slopes condition, simplified short-term surveying monitoring with intensive development of ledges deformations of slopes in individual sections or sides of the open pit, high-precision instrumental monitoring along profile lines along the deformations development of the open pit sides, surveying for the certification purpose of landslides and collapse of benches, systematic surveying control over compliance with the planned parameters of the benches and sides slopes.

Much work on improving the methods of instrumental monitoring in different years was carried out by Kazakhstani scientists: Popov I.I., Okatov R.P., Baklanov E.V., Nizametdinov F.K., Ozhigin S.G. $[8,9]$ and others. It is proposed to transfer the elevation from one ledge to another by geometric leveling with an inclined sighting beam, for this E.V. Baklanov [5] developed a leveling attachment to be worn on the lens barrel. The methods of instrumental monitoring along the profile lines with the use of a light range finder, photogrammetric survey, electronic total station and a laser scanner have been tested in open pits [12-15].

Employees of the SPMU Research Center (St. Petersburg, Russia) have developed a number of laser devices that can be successfully used in mine surveying and geodetic works in open fields. An example is a small-sized laser attachment for telescopes of theodolites and levels, designed for prompt transfer of theodolite or 
level to the mode of operation of a laser pointer, laser theodolite or level $[3,11]$.

The disadvantages of the methods for the instrumental surveys production performed by traditional mine surveying tools are the laboriousness of field and office work, the inability to fully cover the monitoring of inaccessible and dangerous places on the slopes of the quarries ledges and sides, the inexpediency of setting up and carrying out work on monitoring stations on short-term existing work sites and steep slopes of working benches, the difficulty of surveying the surface of the landslide massif, as well as the large amount of time spent on observing objects with a height difference of up to $200 \mathrm{~m}$ and more.

Based on the analysis of literary sources on instrumental control over the state of stability of the near-sides massifs of open pits, it can be concluded that in the development of deposits the organization of systematic mine surveying instrumental monitoring should be given paramount priority.

Analysis of the methods of instrumental monitoring of the quarry slopes state and the accuracy of their measurements (Table 1) shows the need for their further improvement using modern measuring instruments and their combination: an electronic total station, a laser scanner, radar interferometry, global satellites of systems and information processing technologies.

Table 1

Methods of survey with root-mean-square measurement errors

\begin{tabular}{l|l|c|c|c}
\hline \multirow{2}{*}{ № } & \multicolumn{1}{|c|}{ Mine survey method } & $\begin{array}{c}\text { Distance from } \\
\text { reference to } \\
\text { working } \\
\text { marks, } \mathrm{m}\end{array}$ & \multicolumn{2}{|c}{$\begin{array}{c}\text { RMSD for determining } \\
\text { the position of points, } \mathrm{m}\end{array}$} \\
\cline { 4 - 5 } & & 100 & 0,250 & 0,020 \\
\hline 1 & Total station & 100 & 0,010 & 0,002 \\
\hline 2 & $\begin{array}{l}\text { Geodetic monitoring along } \\
\text { profile lines and leveling of the }\end{array}$ & 100 & 0,030 & 0,010 \\
\hline & $\begin{array}{l}\text { III class } \\
\text { Phototheodolite with } \\
\text { graphomechanical image } \\
\text { processing }\end{array}$ & 100 & 0,008 & 0,004 \\
\hline 4 & $\begin{array}{l}\text { Method of convergent } \\
\text { phototheodolite survey with } \\
\text { differential determination of } \\
\text { point offsets }\end{array}$ & & \\
\hline
\end{tabular}




\begin{tabular}{c|l|c|c|c}
\hline 5 & $\begin{array}{l}\text { Air stereophoto-grammetric } \\
\text { method with graphomechanical } \\
\text { processing }\end{array}$ & 100 & 0,030 & 0,030 \\
\hline 6 & $\begin{array}{l}\text { Aerial photogeodetic with } \\
\text { analytical processing of images }\end{array}$ & 100 & 0,007 & 0,011 \\
\hline 7 & Laser scanning & 100 & 0,050 & 0,050 \\
\hline \multirow{2}{*}{8} & Interferometry: & 1 Pixel & 0.001 & 0.500 \\
& satellite & & 0,050 & 0,001 \\
\hline 9 & ground & 100 & 0.010 & 0.010 \\
& kPS: static & 0.020 & 0.020 \\
\hline
\end{tabular}

\section{The basics of creating automated monitoring system of the open pit slopes stability}

The existing experience of instrumental mine surveying monitoring of the state of stability of the open pits near-sides massifs in the deposit fields of Kazakhstan by the Karaganda school of geomechanics and mine surveyors made it possible to develop and implement a high-performance monitoring technique using modern electronic equipment (Fig. 1).
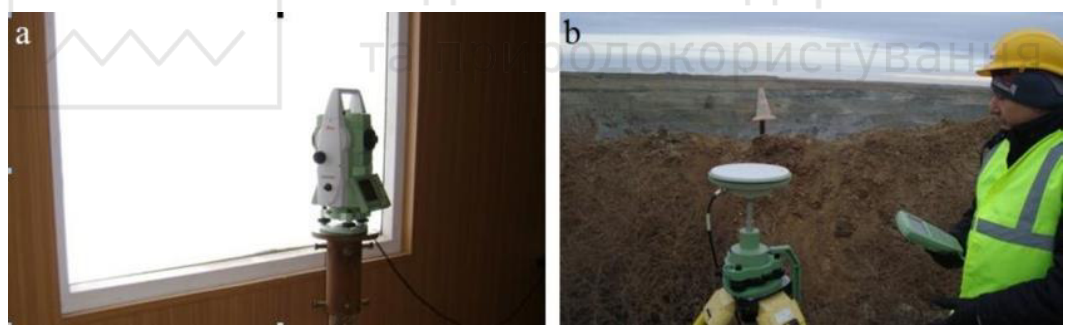

Fig. 1. Modern technologies of high-precision monitoring at quarries: $a$ - an automated monitoring point with an electronic total station; $b$ - monitoring using GNSS

To study the state of the near-sides massifs in open pits, innovative methods of instrumental monitoring using electronic total stations, GPS systems, a mining laser scanner and a ground penetrating radar were used.

Based on the tasks and functions of managing the stability of quarry slopes in the development of mineral deposits characterized by the diversity and variability of the geological structure, it is necessary to constantly conduct research aimed at obtaining reliable information about the structural features of the near-sides massif, 
its strength properties, hydrogeological conditions, etc. Such studies should be carried out at all stages of the formation of slopes of open pits benches and sides (construction of a quarry, development of the planned capacity, the beginning of the design of stationary sides of a quarry on the limiting contour, completion of a quarry) within a single system. The criterion for the correctness of previously adopted technological solutions for the parameters of open pit slopes is high-precision instrumental control over the condition of the open pits and dumps sides, therefore it must also be included in the unified system of mine surveying and engineering-geological research. As a result of comprehensive studies, it is possible to assess and predict the geomechanical processes occurring in the near-sides massifs and develop recommendations on the parameters of open pit slopes in order to improve the efficiency and safety of mining operations. Based on the aforesaid, this system can be characterized by a single name geomechanical monitoring.

Geomonitoring should include:

- obtaining complex engineering and geological characteristics of the composition and physical and mechanical properties of rocks in open pits, dumps and their foundations for calculating the stability and predicting the reliability of managing the state of the rock mass;

- study of the structural and tectonic features of the being developed deposits for calculating the stability of open pit slopes and managing the state of the near-sides massifs;

- study of the development dynamics of geomechanical processes in open pits and dumps slopes for the development of antideformation measures;

- engineering-geological and geomechanical complex of works for the study, forecast and control of the state and properties of openpit and dump massifs, which makes it possible to control the parameters of open-pit slopes during the design, construction, operation and liquidation period, as well as ensuring the industrial and environmental safety of mining operations;

- substantiation and development of an effective technology and methodology for integrated monitoring of opencast mining; 
- recommendations for the operational change of the technological schemes' parameters of open-pit and dump sides elaboration and their development;

- substantiation of measures and technical solutions to ensure the safety of mining operations, their technical and economic efficiency.

2 Instrumental control over the state of quarries massifs stability

The main requirements for the production of mine surveying monitoring of the slopes condition in open pits are set out in the instructions of VNIMI [6]. In accordance with it, in open pits it is necessary to carry out a full range of measures for instrumental control over the condition of the slopes of the open pits' benches and sides.

\subsection{Monitoring of the open pit sides displacement using an electronic total station}

The use of an electronic total station for instrumental monitoring (Fig. 2) makes it possible to determine the position of the working benchmarks in space and build a picture of the vector displacement of the benchmarks taking into account time. In this case, it becomes necessary to determine the magnitudes of errors that arise during measurements.

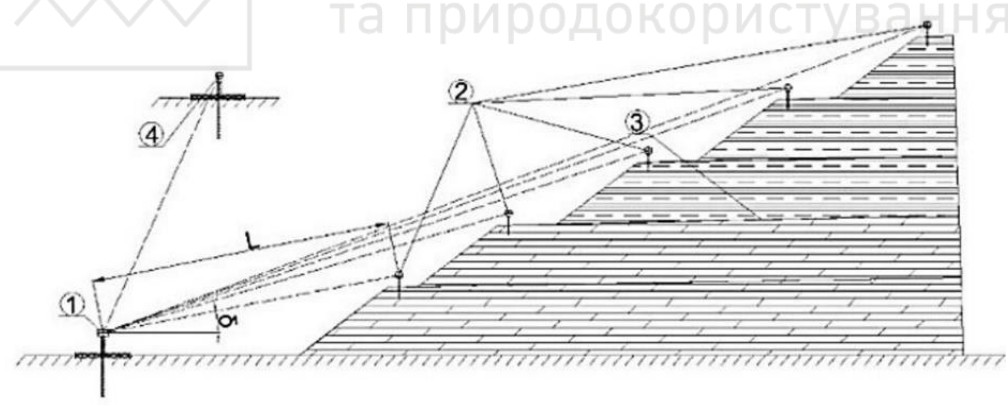

Fig. 2. Surveying the position of the working benchmarks from the support pylon: 1 - electronic total station mounted on a support pylon; 2 - working benchmarks with optical prisms; 3 - open pit side; 4 - orientable support pylon; $L$ - the distance to the observed reflector; $\delta$ - tilt angle up to the observed working benchmark

The accuracy of the transmission of an elevation mark by an electronic total station is determined by the error in calculating the excess by trigonometric leveling according to the formula, $\mathrm{mm}$ 


$$
m_{h}^{2}=L^{2} \cos ^{2} \delta \frac{m_{\delta}^{2}}{\rho^{2}}+m_{L}^{2} \sin ^{2} \delta+2 m_{V}^{2},
$$

where $m_{\delta}, m_{L}, m_{V}$ - the root mean square errors of the vertical angle, distance and height of the instrument and reflector.

The first term on the right side is the excess error due to the error in measuring the vertical angle $\delta$ not exceeding $45^{\circ}$. Errors in determining the excess at vertical angles of $15^{\circ}, 30^{\circ}, 45^{\circ}$ have almost the same value at a distance of up to $500 \mathrm{~m}$, therefore, during measurements it is necessary to maintain this value.

The error of the planned position of the working benchmarks is determined by the formula, $\mathrm{mm}$

$$
m_{p}^{2}=\frac{m_{\beta}^{2}}{\rho^{2}} L^{2}+m_{L}^{2}+m_{C}^{2}+m_{F}^{2}+m_{I D}^{2},
$$

where $m_{\beta}$ - the error in measuring the horizontal angle; $m_{L}$ - the error in determining the distance; $m_{C}$ - centering error; $m_{F}$ - the error of fixing the reflector; $m_{I D}$ - initial data error.

The error in fixing the reflector to the working benchmarks depends on the performer, which necessitates the use of rigid plumb lines to center the reflector over the benchmark. In this case, the reflector can be installed with an accuracy of $\pm 0.5 \mathrm{~mm}$. The laser centering error of the total station is $\pm 0.5 \mathrm{~mm}$.

The analysis of the methods for determining the benchmarks position showed that when using the method of double polar intersection and linear-angular intersection, the results are practically the same and both the first and the second methods can be used. The error in determining the position of the working benchmark by the method of polar coordinates, taking into account the influence of all components, will be equal to $m_{p}= \pm 4.1 \mathrm{~mm}$. The calculation of the expected error was made for the working benchmark, located at a distance of $500 \mathrm{~m}$ from the reference one, and the angles were measured at three steps. Knowing the errors in determining the excess and the planned position of the working benchmarks, it is possible to calculate the total error of the benchmark position when measured with an electronic total station, which will be $M_{t o t}= \pm 4.9$ $\mathrm{mm}$. 
Compliance with this condition in determining the position of the initial benchmarks in current and prospective systematic monitoring allows for a unified approach and the same measurement accuracy.

\subsubsection{Instrumental monitoring schemes}

For high-precision instrumental monitoring using an electronic total station, schemes have been developed for conducting monitoring along a profile line for working benchmarks from reference and tie points, which allow to ensure the required accuracy under various mining and technical conditions of field development (Fig. 3,4,5).

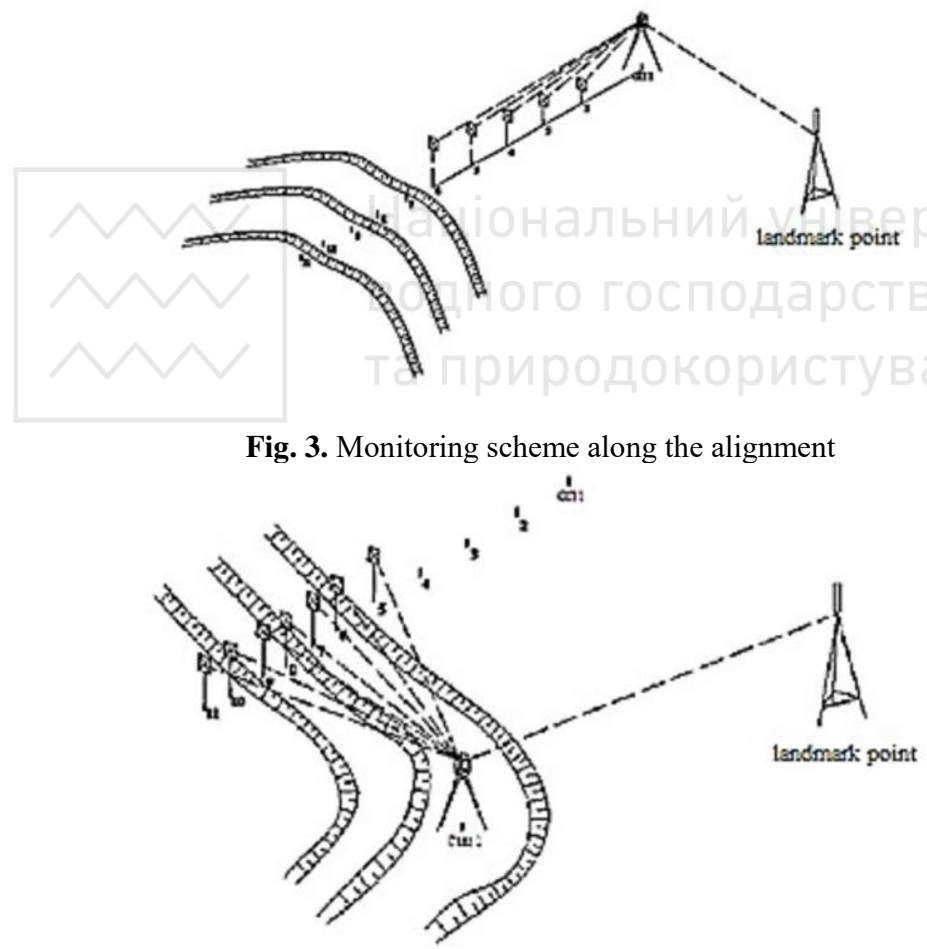

Fig. 4. Monitoring scheme from tie points 


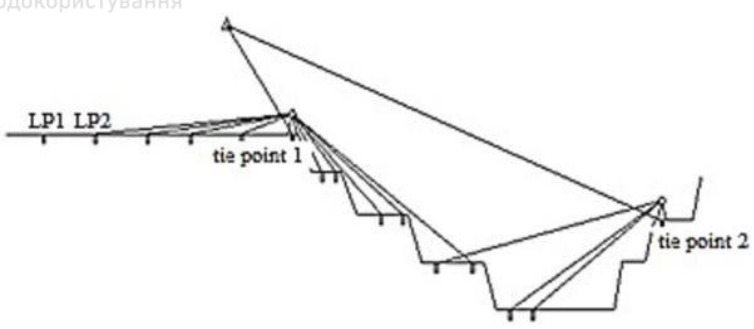

Fig. 5. Monitoring scheme from the opposite side of the quarry

When carrying out systematic instrumental monitoring in open pits, one of the important conditions for fast, accurate and error-free work is the development of a unified scheme for binding and orienting the reference and tie marks of profile lines for the operator of an electronic total station and a scheme for the location of working marks relative to reference points for mine surveyors with reflectors.

A method is proposed for monitoring the state of the quarries mass by placing a benchmark with a reflecting plate in the slope, using the technology of pulse measurements based on the reflectionless function of an electronic total station.

For this method, monitoring scheme has been developed, where the working benchmarks are located along the entire length of the profile line, and the reference benchmark at the base of the quarry or on the opposite side of the quarry in the alignment of the working benchmarks, taking into account the angle of sight on the plates not more than $30^{\circ}$.

It was revealed that at small angles of incidence (from $0^{\circ}$ to $30^{\circ}$ ), the error does not exceed the permissible measurement accuracy with a reflectorless total station.

\subsection{Monitoring of the quarries massif displacement using a laser scanner}

The essence of terrestrial laser scanning (TLS) (Fig. 6) is to measure at a high speed the distances from the scanner to the points of the object and register the corresponding directions (vertical and horizontal angles), therefore, the measured values during terrestrial laser scanning are the same as in operation with electronic total stations. However, the principle of total shooting of an object, and 
not of its individual points, characterizes the TLS as a survey system, the result of which is a three-dimensional image, the so-called scan.

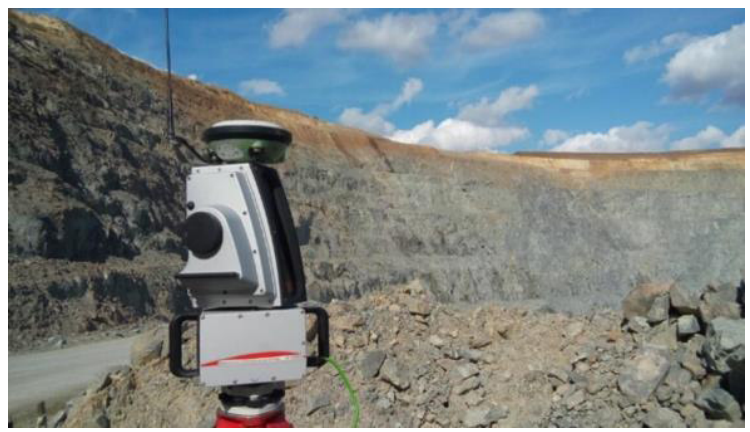

Fig. 6. Mining Laser Scanner

The system for terrestrial laser scanning consists of an TLS and a field personal computer with specialized software. The TLS consists of a laser rangefinder adapted for high frequency operation and a laser beam sweep block.

The spatial coordinates of the object points in the TLS coordinate system are calculated by the formulas

$$
X=R \times \cos \varphi \times \sin \theta ; Y=R \times \sin \varphi \times \sin \theta ; Z=R \times \cos \theta
$$

where $R$ - the measured distance from the point of the scanner to the object; $\varphi$ - the horizontal angle of the measured direction of the laser beam $R ; \theta$ - the vertical direction angle $R$, measured from the Z-axis to the vector $R$ (zenith distance of the laser beam direction).

The procedure for performing measurements with a laser scanner is produced in the following sequence:

- install a laser scanner over the reference point with known coordinates;

- centered on a point using an optical plummet;

- leveling the device due to the built-in electronic compensator, which significantly increases the leveling accuracy;

- carry out the adjustment of the laser scanner using a field tablet with special software;

- input atmospheric corrections, taking into account pressure, air temperature and relative humidity (for high-precision measurements of distances, the atmospheric correction must be determined with an accuracy of $1 \mathrm{ppm}(1 \mathrm{~mm}$ per $1 \mathrm{~km})$, air temperature - with an 
accuracy of $10^{\circ} \mathrm{C}$, atmospheric pressure - up to 3 mbar, relative humidity - up to $20 \%$ ).

- input name and coordinates of the scanner position, tool height, name and coordinates of the scanner orientation point;

- perform orientation of the device;

- enter the program measurement mode, where the scanning area of the device is selected and the measurement is started.

To organize instrumental monitoring at a quarry, it is necessary to decide the following:

$a$ - select potentially unstable or landslide areas based on the analysis of engineering-geological and mining-technical conditions of development to determine the scanning sites;

$b$ - to take out the reference points of the monitoring stations in nature and lay the benchmark;

$c$ - to carry out the binding of reference points (determination of coordinates $X, Y, Z)$ to the nearest points of the mine surveyor geodetic reference network;

$d$-make a laser scan of the selected area;

$e$ - process the results of laser scanning and analyze them.

The obtained volumetric electronic version of the quarries massif is processed on a computer in order to obtain the parameters of the occurrence of cracks and discontinuous breaches: angles of incidence and strike, the sizes of structural blocks formed by cracks, as well as comparison of the digital model (Fig. 7) when scanning the same section of the quarries massif repeatedly.

The data acquisition module is responsible for collecting data in real time, monitoring measurements and measuring cycle, checking the permissible values of monitoring displacements.

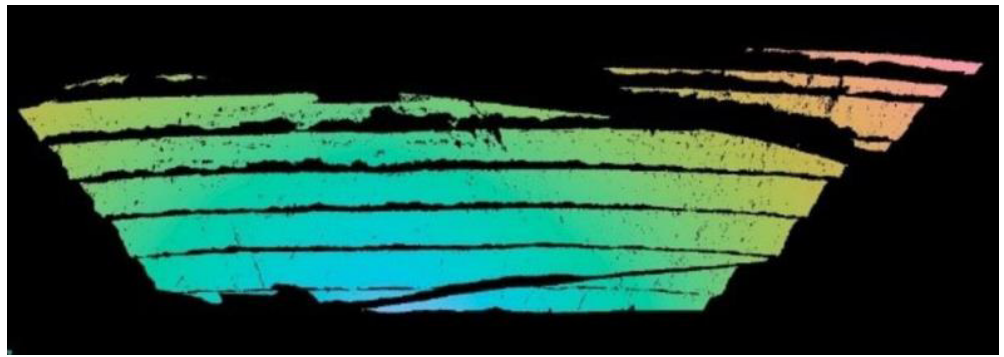

Fig. 7. Checking the presence of collapses of the investigated part of the quarry boards using a digital model 
The received data analysis module is responsible for the analysis of the measured data, reporting, editing and post-processing. Results can be presented in digital and graphical form with soundtrack.

\subsection{Monitoring of the quarry sides displacement using global navigation satellite systems (GNSS)}

The application of methods for determining the position by GNSS signals for mine surveying and geodetic purposes in Kazakhstan began in 2000. During the period of their use, significant advantages were revealed in comparison with traditional mine surveying methods. These include a wide range of accuracy, independence from weather conditions, time of day and year, from mutual visibility between benchmarks, high automation, the ability to work continuously and in motion.

At the same time, the use of satellite methods in practice revealed a number of disadvantages: dependence on obstacles, vulnerability to radio interference, expensive equipment, but especially the need to adjust the theory and practice of mine surveying to observe the movement of slopes along profile lines.

In this regard, to improve the efficiency of the mine surveying application of GNSS in open pits, the following tasks must be solved:

- study GNSS measurement errors and develop methods for their reduction;

- to develop a methodology for monitoring the deformations of the quarry sides with modern mine surveying instruments;

- to improve the design of GNSS receivers to reduce measurement errors when observing the quarry sides.

At most mining enterprises, where deformations are measured at monitoring stations for fortified objects, there is a difficult or poorquality reception of satellite radio signals. The main unfavorable factors in this case will be electrical noise, shadow effect from the slope and limited visibility to satellites. The unfavorable effect of electrical noise can be excluded even at the design stage of the monitoring station, in this case it is necessary to avoid laying working and reference benchmarks closer than 25-50 meters from power lines, transformer substations and the contact network of 
electric transport. GNSS receiver errors depend on its installation and centering.

When observing the movement of slopes along profile lines in open pit mines, the error of the user signal can be reduced due to the correctly selected measurement technique.

The results of measurements in the "kinematics" mode to study the effect of "multipath" on the measurement accuracy at different positions in height showed that when measuring in the kinematics mode, the measurement accuracy decreases by $25 \%$ with increasing tripod height. The use of a metal disk when measuring in the kinematic mode increases the horizontal measurement accuracy by $17 \%$, in the $X$ axis by $27 \%$, in the $Y$-axis and in height by an average of $36 \%$.

It should be noted that the use of a satellite geodesy complex for observing the process of displacement of the earth's surface at mining enterprises makes it possible to conduct research at a qualitatively higher level. The measurements carried out by the GNSS complex have shown high efficiency for solving the problems of geomechanics, thanks to its use, it became possible to regularly monitor deformations and stresses occurring in the earth's crust.

According to the data obtained from the study of the influence of the "shadow effect" on the accuracy of GNSS measurements, it can be concluded that the measurement error increases when moving to the slope. Knowing the height of the slope and the permissible distance from the slope, it is possible to derive the formula for the permissible position of the working benchmark for planned and altitude determination

where $H$ - the slope height, $\mathrm{m}$.

$$
m_{\text {perm }}=0,292 \times \mathrm{H} \text {, }
$$

This formula should be used when planning the laying of monitoring lines for the displacement of slopes using GPS systems.

\subsection{Monitoring of the quarries sides displacement using the GeoMoS system}

The GeoMoS system controls sensors in a fully automatic mode, at a great distance from the data collection and processing site. The automated system allows high speed measurement cycles and eliminates human error. The operator is required to conduct a qualitative analysis of the results in order to select the necessary 
monitoring means, their location and connection into a single network.

Having constantly updated parameters of the observed object, it is possible with a high degree of reliability to make forecasts of its state, to prevent possible accidents.

The system consists of two software subsystems - Monitor and Analyzer. Monitor (Fig. 8) is responsible for real-time data collection, control of measurements and the measurement cycle, validation of acceptable values, monitoring of messages.

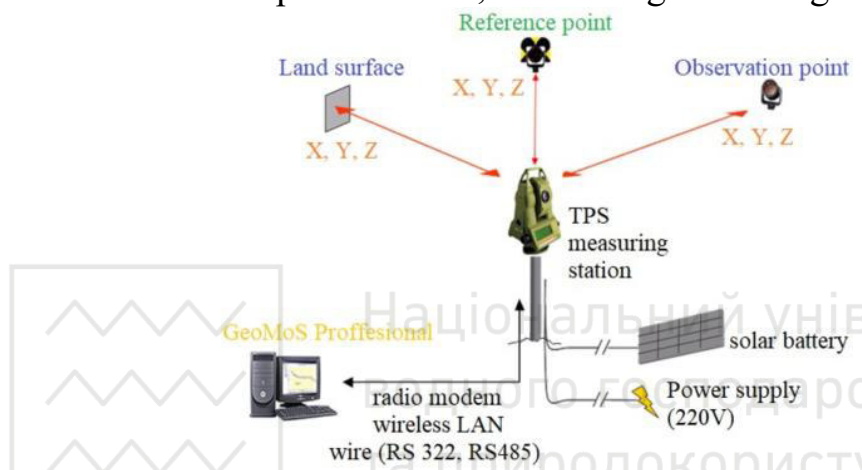

Fig. 8. Measuring cycle principle of the Monitor subsystem

The Analyzer is responsible for analyzing the measured data, reporting, editing and post-processing. Data and results can be presented numerically and graphically, as shown in Fig. 9, and exported in various standard formats.

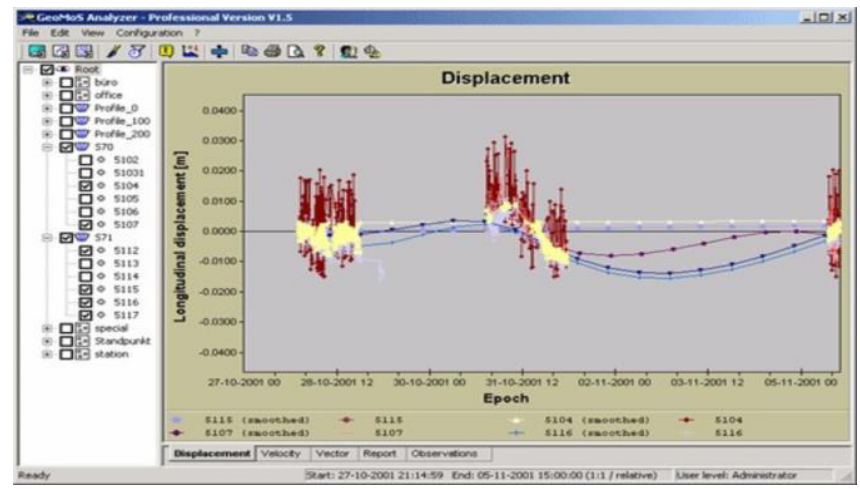

Fig. 9. Graphical and numerical presentation of measurements and results of the Analyzer subsystem 
The hardware component of the GeoMoS monitoring system is various data collection devices: total stations of the TPS1200, TPS1800 and TPS2003 series; GPS System 500; meteorological sensors.

The device is located in the measuring booth, which is designed to protect the instrument (Fig. 10).
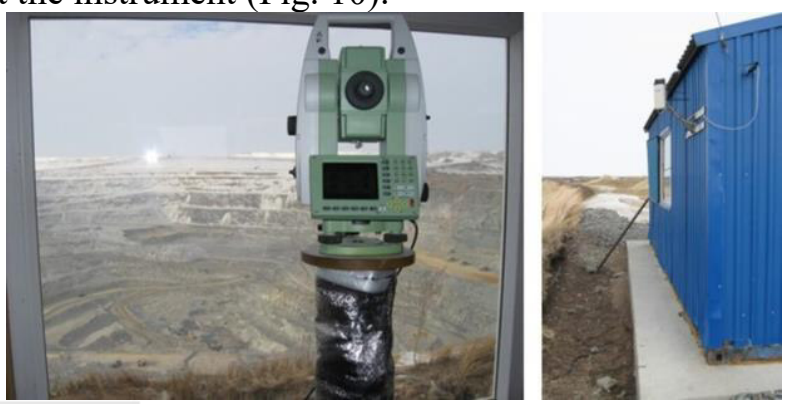

Fig. 10. GeoMoS monitoring station

The results of the Analyzer system are: displacements (longitudinal, transverse), displacement velocities, displacement vectors (in plan and height).

The measuring booth must be equipped with climate control for the smooth functioning of the system. Climate control is important to avoid extreme temperatures, humidification and condensation.

Main technical characteristics of the GeoMoS system:

- modular configuration from one to several stations;

- the ability to connect and combine a large number of measuring stations into one system;

- remote access to work and change settings;

- messages about the current state of the system (exceeding critical displacements of the object, lack of power, hacking or destruction);

- modeling the meteorological net around the measurement object;

- recording the changes made during editing and post-processing;

- parallel use of several devices (total stations, GPS, metrological and geotechnical sensors);

- automatic regulation and synchronization of data reception via cable, radio modem, LAN, WAN or via the Internet; 
- the ability to measure distances over a long range (up to $5 \mathrm{~km}$ );

- a powerful set of tools for graphical and digital data analysis;

- transmission of messages by e-mail or digital interface;

- import-export to other systems (ASCII, DGN, WMF, Excel);

- support for large databases with an interface (SQL-Server);

- data archiving.

The position of the initial benchmarks in the created monitoring system must be determined either by a double polar intersection, or by a linear-angular intersection from the reference survey-geodetic network points. All measurements with an electronic total station, in order to improve accuracy and eliminate gross errors, should be performed in 3 steps. Acceptance of measurement includes one aiming at a reflector, in which several readings are taken. The weighted average value of the measurements is taken as the final result, while the difference between individual readings should not exceed $\pm 2 \mathrm{~mm}$.

Compliance with this method of determining the position of the initial benchmarks in the conditions of current and future systematic monitoring allows you to have a unified approach and the same accuracy of the work performed.

3 Implementation of geomonitoring systems for quarries massifs in Kazakhstan

In 2008, on the basis of geomechanical research of the quarries and dump massifs of the Sarbaiskiy (Fig. 11), Sokolovskiy and Kacharskiy open pits, projects of monitoring stations were developed for the state of stability of their quarries and dumps sides, and in 2013 monitoring stations were laid at the "Kurzhunkolskiy" open pit.

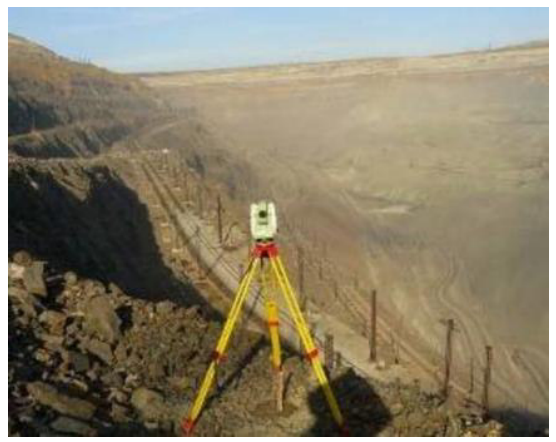

Fig. 11. Instrumental control of the western side of the "Sokolovsky" quarry 
The projects consider the issues of creating a geomonitoring system based on instrumental surveying and geodetic monitoring of displacements and deformations of massifs according to the established benchmarks of the monitoring stations profile lines using an electronic total station and GPS receivers of a satellite positioning system.

The selection of sites for laying benchmarks of monitoring stations was made based on the analysis of the geomechanical situation in the open pits. The design and length of the profile lines have been determined. The design of monitoring and control points, reference and working benchmarks of profile lines has been developed.

The total number of profile lines of the "SSGPO" JSC open pits geomonitoring system is 41, including for open pit mines: Sarbaisky - 10 profiles, Sokolovsky - 15 profiles, Kacharsky - 16 profiles. The total number of benchmarks - 1728 pieces, of which reference benchmarks - 50 pieces, including for quarries: Sarbaisky - 575 benchmarks, of which reference - 14, Sokolovsky - 397, of which reference - 16, Kacharsky - 756 benchmarks, of which support -20.

The objects of Zhairem GOK include the Ushkatyn-III, Zhairem, Zhomart deposits, which are mined by open pits: Ushkatyn-III, Zapadny, Dal'zapadny open pit №1, Dal'zapadny open pit №2 and Zhomart.

Based on the analysis, in 2002, nine monitoring stations were established at the open pits of the Zhairem GOK. For example, the baritelead part of the Ushkatyn-III open pit is currently in a state of temporary conservation. Special slope making measures were not carried out on the side of the open pit, therefore, to establish their feasibility, a monitoring station I was established. The analysis of the geomonitoring results of the quarries massifs state of the Zhairem GOK, carried out at nine monitoring stations for four years (2002-2005), showed that the deviations of the coordinates of the working benchmarks from their initial position are within the measurement accuracy. There are some local deformations of the benches slopes in the open pits, while the deformations of the sides are not generally established.

Based on the studies carried out in 2018 in certain areas of the quarries massifs of the "Vasilkovsky" open-pit mine (Fig. 12), where the mining depth reached 260 meters, the following conclusions were made: the upper clay slopes of the ledges are fairly reliably beveled, 
in the weathering crust's middle part the slopes of the ledges are folded semi-rock breeds and special slopes making works were not produced (there are individual local rock falls and overhangs), and the lower slopes of the ledges, composed of rocky breeds, are set using the technological diagrams of the slopes making and look quite reliable from the point of view of stability. The concern here is caused by the quarry's massifs, complicated by tectonic faults and, according to the falling fractures, diagonal to the slope.

The stability assessment of the anisotropic slope of a $30 \mathrm{~m}$ high ledge with an inclination angle of $65^{\circ}$ at $85 \mathrm{~m}$ horizons of the southern side of the open pit was carried out. The initial geometric base (elements of occurrence of cracks and discontinuous breaches from the mirror sliding surface) was obtained by scanning with a laser scanner. Average values of the parameters: the strike azimuth of the fault (A) $249^{\circ}$ and the angle of inclination $(\delta) 43^{\circ}$, and the fractures $A=179^{\circ}$ and $\delta=87^{\circ}$, and the azimuth of the strike of the slope $A_{\text {slope }}=285^{\circ}$.

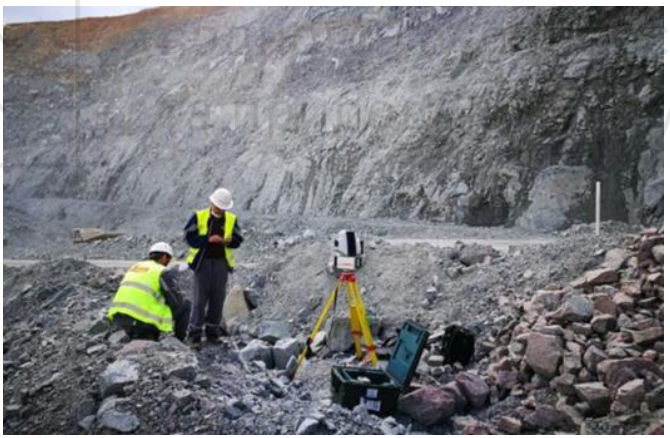

Fig. 12. Laser scanning in the "Vasilkovsky" quarry with the HDS 8800 mining scanner

Knowing the geometrical parameters of the slope and calculating the parameters of the collapse prism, it became possible to determine the strength characteristics: adhesion along a fault, equal to $2.5 \mathrm{t} / \mathrm{m}^{2}$ and $\rho^{\prime \prime}=20^{\circ}$, and along a breaking crack: adhesion $5.5 \mathrm{t} / \mathrm{m}^{2}$ and $\rho^{\prime \prime}=23^{\circ}$. The obtained strength characteristics were used to assess the stability of a neighboring rock block of a similar nature, which showed that the safety factor is equal to: 5.90 at a bench slope height of $30 \mathrm{~m}$ and 2.90 at a bench slope height of $60 \mathrm{~m}$. This indicates its stable 
state, according to the methodological instructions [7]. Inspecting the slope surface according to laser survey data in this area, it can be argued that other possible weakening surfaces do not affect the stability of the rock mass, and the previously assumed crack is not detected.

Data processing of the obtained monitoring results at the Kentobe iron ore quarry, changing in the lengths of the intervals between the benchmarks, i.e. horizontal spacing $d S$ between the benchmarks relative to the initial values, the offset of the benchmarks relative to the reference marks at each station $(\Delta L)$. From these displacements, one can judge the presence of displacements of the quarries massif, composed of clay deposits. The deformation of the massif is confirmed by the presence of vertical displacements at station " $A$ " within $-10 \mathrm{~mm}$; at station " $B$ " is -29 $\mathrm{mm}$, and at station " $C$ " within $-26 \mathrm{~mm}$. The array also shifts along the coordinates $\Delta X, \Delta Y$ relative to their original position.

Conclusions. Thus, forecasting and ensuring the stability of the benches and the sides slopes of the quarries is one of the most important tasks when conducting open pit mining. At the same time, special attention is paid to the creation of a system of integrated instrumental control over the state of the quarries massifs in open pits, and systematic monitoring allows:

- in a constant mode to receive operational information about the processes occurring in the rock mass;

- send signals about an increase in deformations to all the main services of the enterprise;

- promptly develop measures to prevent landslides and emergencies;

- to determine the frequency of instrumental surveying monitoring according to the data of the displacement of the profile lines reference marks.

Therefore, the work considers the existing digital measurement technologies to determine the displacements of the rock mass:

- the basics of creating automated systems for monitoring open pit slopes;

- instrumental control along profile lines using an electronic total station: the resulting measurement errors and the implemented monitoring schemes;

- laser scanning of the most dangerous areas of the quarries arrays with a mountain scanner and comparison of two or more digital scans; 
- use global satellite systems during monitoring of benchmarks laid down along profile lines;

- implementation of the GEOMOS system complete with a robotic total station and optical prisms.

Modern methods of instrumental monitoring have been introduced and tested at the open pit of the following mining enterprises: "SSGPO" JSC, "Altaypolimetals" LLP, "Kazakhmys Corporation" LLP, "Altyntau Kokchetau" LLP, "Zhairemsky GOK” JSC, "Shubarkolkomyr" JSC, "ORKEN: Kentobe, Atansor and Lisakovsk" LLP and others.

References

1. Fisenko, G.L. (1965) Stability of the sides of open pits and dumps. Moscow: Nedra.

2. Pevzner, M.E. (1978) Fighting rock deformations in quarries. Moscow: Nedra.

3. Galust'yan, E.L. (1980) Management of geomechanical processes in open pits. Moscow: Nedra.

4. Popov, I.I., Okatov, R.P. (1980) Landslide control in quarries. Moscow: Nedra.

5. Popov, I.I., Nizametdinov, F.K., Okatov, R.P., Dolgonosov, V.N. (1997) Natural and man-made foundations for managing the stability of quarry benches and sides. Almaty: Gylym. 1998).

6. Rules for ensuring the stability of the sides of coal mines. (St. Petersburg, VNIMI,

7. Guidelines for observing the deformations of sides, slopes of benches and dumps in open pits and the development of measures to ensure their stability. (Approved by the MES of the RK dated 2008).

8. Dolgonosov, V.N., Shpakov, P.S., Nizametdinov, F.K. et al. (2009) Analytical methods for calculating the stability of quarry slopes. Karaganda: SANAT-Polygraphy.

9. Popov, V.N., Shpakov, P.S., Yunakov, Yu.L. (2008) Quarry slope stability management. Moscow: MGGU.

10. Nesmeyanov, B.V., Nesmeyanova, Yu.B. (2012) Stability of quarry walls in the course of sequential underground-open-pit development of deposits. Moscow: MGGU.

11. Nizametdinov, F.K., Portnov, V.S., Nizametdinov, N.F. (2007) Modern methods of instrumental monitoring of the open pit slopes state. Karaganda: SANAT-Polygraphy.

12. Ozhigin, S.G. (2009) Management of the stability of the rock massifs in the open pit mines of Kazakhstan. Karaganda: SANAT-Polygraphy.

13. Opportunities of Geodetic Monitoring on the Example of Current Projects in Eastern Europe. (Germany, Aachen, 2013)

14. Nizametdinov, F.K., Ozhigin, S.G., Nizametdinov, R.F., Ozhigina, S.B., Nizametdinov, N.F., Khmyrova, Ye.N. (XV International ISM Congress (International Society for Mine Surveying) 2013) State and prospects for the development of geomechanical support for open pit mining. (Vol. 1) Deutscher Markscheider-Verein e.V. - DMV.

15. Galperin, A.M. (2003) Geomechanics of open pit mining. Moscow: MGG U. 